\title{
Chapter 1 \\ Introduction: Preparing the Way \\ for Qualitative Research in Migration Studies
}

\author{
Ricard Zapata-Barrero and Evren Yalaz
}

"An attitude of moral indifference has no connection
with scientific 'objectivity"

Max Weber

The Methodology of the Social Sciences (New York: Free Press,

[1905] 1949, 60)

Migration is not only transforming sending, transit, and receiving countries, but also social scientific studies. The expansions of human mobility, profound demographic transformations, and their diverse social, political and economic consequences have brought unprecedented theoretical and empirical attention to the phenomenon. While migration research has relatively longer and more established tradition in US academia, its growth in European scholarship in the last three decades has been remarkable. An increasing number of scholars and journals devote their work to understanding causes and consequences, current situations, changes and continuities of migration-related issues in Europe. Moreover, the expansion of research centres and networks, undergraduate and graduate programs, conference meetings, winter and summer schools demonstrate increasing institutional visibility of migration research. For instance, IMISCOE (International Migration, Integration, and Social Cohesion), which is currently Europe's largest network of scholars in the area of migration and integration, has grown from 19 founding member institutes in 2004 (Brus 2014) to 39 member institutes in 2017 and over 500 individual members. On the other hand, what is less evident is the systematic attention to the methodological issues in European migration studies ${ }^{1}$. This edited volume presents an

\footnotetext{
${ }^{1}$ There have been ample textbooks that primarily focus on qualitative research in social sciences, such as classic works of Strauss and Corbin (1990) and Denzin and Lincoln (1994) and as well as more recent qualitative research handbooks of Beuving and de Vries (2015) and Yin (2010). While

R. Zapata-Barrero $(\bowtie) \cdot$ E. Yalaz

Political and Social Sciences Department, University of Pompeu Fabra - GRITIM-UPF,

Barcelona-Catalonia, Spain

e-mail: ricard.zapata@upf.edu; evren.yalaz@upf.edu
} 
effort to address this gap, through the collaboration of migration scholars from diverse disciplines. It is a unique volume as it brings together a multidisciplinary perspective as well as illustrations of different issues derived from the research experience of the recognized authors.

The publication is particularly addressed to graduate and post-graduate students and, more generally, to those who embark on the task of doing qualitative research for the first time in the field of immigration. It is also addressed to more senior researchers who are interested in strengthening their competence in the use of qualitative methods, specifically applied to the study of migration processes. In a nutshell, each chapter provides the readers with a set of substantial reflections that we hope will guide them in dealing with the particular aspects of qualitative research when applied to migration studies. While covering different stages and topics of migration research, each author explores when and why a particular dimension of qualitative research becomes key to migration questions; how it adopts different logics, designs, and techniques; what kind of theoretical, epistemological, empirical, and ethical challenges researchers in this field face; and how these challenges can be addressed, and possibly lessened or at least controlled.

This edited volume is primarily concerned with the issues of qualitative methodology and its diverse research techniques in migration studies. The central focus neither assumes a hierarchy among different methodological traditions nor carries any intention of unilaterally imposing norms of one methodological tradition over others. In other words, qualitative methodology neither can be seen as inherently superior to other methodological traditions nor as a "last resort" technique when statistical methods are not appropriate (Mahoney 2007, p. 122). What current research shows is that scientific excellence and academic development go hand in hand with the use of diverse methodological tools, approaches, and designs. In this respect, we acknowledge the complementarity of different methodological paradigms that vary in terms of their strengths and limitations, and appreciate the efforts of multi-method collaborations.

Yet, we also believe that qualitative research has a particular importance for migration studies, considering its potential for producing rich, in-depth, and nuanced analysis; allowing for conceptual refinements with higher validity; redefining the existing categories and generating new hypotheses and even theoretical paradigms; exploring complex, conjunctural, multi-faceted dimensions of the migration dynamics; and last but not least, being better tuned for understanding the voices of social actors and immigrant groups, especially the ones who lack means of participation

this extensive literature on qualitative research highly contributes to social scientific inquiry in general, it lacks an emphasis on migration studies and its special theoretical and methodological needs. On the other hand, few existing works on the area of research methods in migration studies (Iosifides 2011; Vargas-Silva 2012; Voloder and Kirtipchenko 2013; Elliot et al. 2017) either overlook unique issues of qualitative methodology in migration studies or did not address the need for developing special methodological awareness for the European context. 
and representation in mainstream society and politics. Together with these distinct characteristics, most contributors in this volume also show another feature of qualitative research: there is always a certain degree of critical assessment of the reality being under qualitative scrutiny. We believe that these distinctive features of qualitative inquiry are crucial components of migration research.

Most of the migration-related topics, such as border/mobility, diversity/citizenship, integration, incorporation/participation, and discrimination/xenophobia require deep contextual analysis, which could not be folded into already existing analytical frameworks. This complexity is already present in many migration debates related to multi-level analysis, super-diversity, post-migration era, transnational studies, new forms of mobility in Europe, issues of refugees and so on. The authors in this volume, depending on their area of expertise, discuss the key aspects of qualitative research while drawing on their own theoretical, epistemological and empirical inquiries. Therefore, along with methodological guidance, each chapter provides rich empirical examples from diverse topics of migration studies.

Qualitative research is far from being a unified perspective. It is "a generic approach in social research" (Beuving and de Vries 2015, p. 19), covering a wide range of research designs (from single case studies to comparative designs), epistemological approaches (from critical realism to interpretivism) and research techniques (from in-depth interviews, focus groups and participant observation, to analysis of documents and visual data). In most of the cases, the disciplinary diversity of social research is largely translated into different qualitative tools covering political science's expert interviews and document analysis, sociology's organisational fieldwork, interpretive and interactionist research, anthropology's ethnographic fieldwork and participant observation, history's archival research and oral history, and linguistics' discourse analysis. This plurality makes it even more crucial to raise methodological awareness and interdisciplinary dialogue that would acknowledge specific theoretical, epistemological and empirical challenges that migration scholars encounter, and develop innovations to address particular research needs.

While migration studies carry a wide range of focuses, from migrants to host society and its actors, from migration-related policies to public institutions, this edited volume is primarily concerned with qualitative empirical research on migrants, migrant communities, and their interactions with the host society, public and private actors, and stakeholders. In this respect, some important areas of migration research, such as qualitative approaches to studying migration policy making or ethnographic methods to studying administrative institutions dealing with migrants are only tangentially addressed. In return, this migrant-centred and bottom-up approach enables the volume's contributors to unpack the category of migrants, explore its internal diversity, and problematize existing categories and boundarymaking mechanisms. Rather than taking the category of migrants for granted, this volume complexifies it through distinguishing migrants, not only in terms of their country of origin, race, ethnicity, religion, and gender, but also in terms of their patterns of mobility (temporary/permanent stayers, circular migrants, etc.), condition of exit (economic migration, family unification, and forced migration), legal status (naturalized in host country, foreigners, documented/undocumented migrants), 
position in labor market (high skilled, low-skilled), age at migration, and length of stay. In this respect, we acknowledge that migrants highly vary from each other in terms of available political, economic, and social opportunities in their destinations, incurred public reactions, perceptions of inclusion, discrimination, and marginality, and networks and resources to respond back to possible precarious conditions. This volume undertakes the task of exploring methodological underpinnings of qualitative study on such a diverse population and their interaction with the host society, directly or through public and private mediators.

One additional value of this book is its geographic focus on Europe. In this way, it seeks to explore theoretical and methodological issues that are raised by distinctive features of the European context. The border and definition of Europe is a highly controversial matter. As Martiniello and Rath (2014, pp. 11-12) point out, there is no consensus about Europe's geographical extent. While some would restrict Europe to six founding states of the European Community, others would define it as current member states of the European Union. While some would consider the continental peninsula as Europe, including both EU and non-EU countries, others would extent it even further, including Ukraine, Russia, and Turkey. In any way, what becomes evident is that European migration policies become a driver for building a European political community. This also invites a reflection on how to shape the normative contours of the external borders of Europe (Zapata-Barrero 2009). Efforts to define a European identity is a contentious issue (Triandafyllidou and Gropas 2015). For some, Europe constitutes an exemplary union based on common ideals, values, interests, historical legacies and traditions. For others, European identity is quite ambivalent, reflected on its plurality, inconsistency, and contradictions. Europe is seen in a crossfire between diverse national (and even sometimes ultra-nationalistic) claims and uniformity posed by globalisation; between promoters of a common European identity and fluctuation and hybridization of identities; and between supporters of "Fortress Europe" and unprecedented human mobility and emerging transnational ties.

Despite all these viewpoints, in order to facilitate theoretical and empirical research, we continue to argue in favour of the analytical benefits of using Europe as a category of analysis. Historically, US-based scholarship has had a pioneer role in shaping the methodological debates in the field. These debates have often reflected the unique immigration experience of North America. The absence of diverse national political frameworks in the US context has prioritized efforts for devising methodological techniques for researching various immigrant groups in a singlecountry context. Across-place analysis has been limited to comparing different US states. The unique nature of immigration flows, the presence of a host society with a migration background, the lack of interventionist welfare state and laissez-faire nature of immigrant integration, the particular history of race-relations and the legacy of slavery, the extensive jus soli citizenship regime and many other factors has had deep impact on the questions and designs of qualitative research in migration studies in the US. On the other hand, we argue that Europe, despite its ambivalent nature, has a distinct place in international migration studies. Some of these distinctive features include its unique history of state and nation-making, its colonial past 
and its lingering effects, its welfare systems, its varied citizenship regimes and integration policies, its transnational structure, its religious history, and its geographic proximity to hot spots of human mobility, such as the Mediterranean area. This latter being one of the epicentres of how tragic human mobility could be without moral face. We believe that these distinctive features of the European context profoundly shape the key questions, concepts, and research designs of qualitative inquiry, therefore, they can be best addressed through a context-sensitive methodological awareness.

Migration studies often require interdisciplinary knowledge, considering its inevitable link with a wide range of research areas such as citizenship studies, diversity studies, mobility studies, gender studies, cultural studies, religion studies, and urban studies. To address this issue, this book brings together migration scholars coming from different social sciences disciplines, working on diverse areas of migration research, and focusing on different regions and migrant groups of Europe. While each contributor focuses on diverse topics and different stages of research, they all share the common concern of considering the role of qualitative research in European migration studies. They do so by highlighting its key strengths, points of limitations, and ways to address these pitfalls through innovative techniques; by opening the category of qualitative methodology up and presenting its diverse logics and applications across different areas of migration studies and across different disciplines; and by contributing to building a context-based methodological approach that would address to the particular aspects of the European context.

In sum, this edited volume serves as a key reference work that stimulates methodological qualitative reflections and provides a framework for discussing the tools to frame and conduct qualitative research. It mainly serves as an instrumental source, both in regard of information-providing and knowledge-producing. The organization of chapters follows a general logic of qualitative research: beginning with theoretical and epistemological considerations; proceeding with crafting the research questions, developing the categories, selecting the cases, collecting empirical evidence through various techniques, and analysing qualitative data collected through these different methods; and finally calling attention to ethical issues and research/policy relations. We hope that this edited volume will familiarize scholars and graduate students who are learning to be researchers in migration studies with a more comprehensive appreciation of qualitative research tools and approaches. We think the book could also be useful for policy makers and the network of actors and professionals producing information and shaping policies in migration-related issues. What is more, it would also be of interest to scholars in social sciences, since it contributes to the methodological and epistemological debates in traditional disciplines.

After this introduction, in Chap. 2, the editors, Ricard Zapata-Barrero and Evren Yalaz, review the current qualitative migration research in Europe. By conducting paper-by-paper analysis of leading peer-reviewed journals in the field of migration research, they reflect on the current state and overtime development of Qualitative Migration Research in Europe (QMR-E). The chapter maps the continuities and changes taking place in QMR-E with respect to their qualitative research methods, designs, research sites and groups, multi-level analysis, and topics. 
Then the edited volume is structured in four main parts. Part I (Theoretical and epistemological issues, Chaps. 4, 5, and 6) introduces the main theoretical and epistemological issues of qualitative research to first-time researchers. Then, we invite the reader to dive into Part II (Building a qualitative research design, Chaps. 7, 8, and $9)$, where they will review the main reflections that must be addressed to frame the focus and approach of their research design. Part III (Qualitative techniques and data analysis, Chaps. 10,11,12, 13, and 14) will discuss qualitative techniques and analysis of qualitative data in migration studies, before going to the last Part IV (Significant requirements before embarking, Chaps. 15 and 16), where the authors provide some recommendations to researchers before beginning to walk through the qualitative research path, such as the ethical issues of the research/policy dialogue framework.

Part I begins with Chap. 3, where Russell King reflects on the essential character of migration as a space-time phenomenon. He explores the debates on multi-sited research designs and mobile field methods, while particularly focusing on multisited ethnography and its critiques. The last part of the chapter illustrates the relevance of context and multi-sited research designs with reference to the author's research on Albanian migration. In Chap. 4, Maren Borkert deals with the challenging question: why bother with interdisciplinarity in migration research? The chapter highlights promises and pitfalls of research that transcends conventional disciplinary boundaries. She argues that while interdisciplinary migration research fosters scientific innovation by allowing scientists to see connections across fields, in practice, it has undeniable downsides due to a lack of interdisciplinarity in academic systems and publication infrastructures. In Chap. 5, Ricard Zapata-Barrero explores the link between political theory and qualitative research. He underlines that qualitative research complements political theory with 'evidence-based and knowledge-based arguments', and in return, political theory equips qualitative research with 'theoretically-founded arguments within liberal-democratic conceptual frameworks'. To develop the potentiality of this link, the chapter proposes a conflict-based approach. In Chap. 6, Theodoros Iosifides discusses some crucial epistemological issues related to qualitative social research in general and qualitative migration research in particular. The chapter considers the issues of 'social reality' or 'realities', 'truth', interpretative relativity, causality and the dichotomy between interpretation and explanation in qualitative research methods, and then proceeds with more specific matters to qualitative migration research, including power differentials between the research participants and researchers, subjectivity and subjectification of research participants, and the issue of objectivity/subjectivity in qualitative migration research.

Part II of the book starts with Chap. 7, in which Ewa Morawska reviews the key epistemological premises, different research goals and questions, strategies of data collection, and the kinds of knowledge produced by traditional qualitative research. The chapter offers illustrations of the kinds of questions asked through standard methods of qualitative investigation, i.e. interviewing, observations, and document analysis in international migration studies. In Chap. 8, Dirk Jacobs delves into the issue of categorising what we study and what we analyse, and the exercise of interpretation. While qualitative researchers are well equipped in highlighting social complexities and deconstructing categorisations, Jacobs warns researchers to be 
aware of dangers of excessive deconstruction and 'anything goes' stances. Karolina Barglowski, in Chap. 9, presents principles and guidelines of case selection and sampling in qualitative research by cataloguing different types of case selection and their application in selected empirical studies in migration studies. She discusses their merits and disadvantages, while highlighting the three methodological challenges that migration research is confronted with: methodological nationalism, ethnic lens and positionality.

In Part III, Olena Fedyuk and Violetta Zentai, in Chap. 10, explore the role of interview method in qualitative migration research by discussing its different forms, applications and methods of analysing data. They argue that interviews and its various forms allow researchers to discover knowledge that otherwise would remain undetected in formal surveys and other more standardized forms of data collection. The chapter also revisits epistemological debates and methodological challenges in the use of interviews and interview data analysis. Chapter 11 proceeds with the discussion of the use of focus groups in migration research. Annalisa Frisina considers this method as a forum for 'thinking public', which permits researchers to 'understand the process of creating consensus and dissent via interaction'. While outlining principles of how to conduct focus groups, the chapter also sheds light on how to interpret discussions and how to analyse the everyday naturalization of nation, ethnicity and race. In Chap. 12, Paolo Boccagni and Mieke Schrooten overview participant observation in migration studies. They discuss how this method becomes a crucial tool to capture the increasing spatio-temporal complexity of present-day mobility. The chapter concludes, with the insights on multi-sited ethnography, the relationship between ethnographers and their counterparts, and promises and pitfalls of online ethnography in social research on migration. In Chap. 13, Teun van Dijk introduces some discourse analytical methods for the study of migration. The chapter provides a brief introduction to Discourse Studies and proceeds with characterisation of Migration Discourse and a more systematic method for the study of migration discourse. Koen Leurs and Madhuri Prabhakar, in Chap. 14, offer their reflection on doing digital migration studies. After distinguishing various paradigms of digital media studies, the authors present the methodological research principles of digital migration studies with a commitment to social justice.

The last part of the book, Part IV, raises the issues that migration researchers will encounter within all stages of their research. In Chap. 15, Ilse van Liempt and Veronika Bilger present ethical considerations in migration studies by particularly focusing on research on smuggled migrants. The chapter gives insights on how to get access to participants, how to build trust, and how participants' narrations might be influenced by external factors such as; migration experience, migration policies and administrations, smugglers or the migrant community itself. Last but not least, Peter Scholten, in Chap. 16, explores how migration research and policymaking can interact in different ways. The chapter argues that various factors at the European, the national, and the local level can shape different configurations of research-policy relations. As the author points out, while the strong interdependency of research-policy relations may have the result of constraining the effect of research questions and methodologies in migration research, we can expect that a more reflective relation will produce more critical reflections on migration research. 


\section{References}

Beuving, J., \& de Vries, G. (2015). Doing qualitative research: The craft of naturalistic inquiry. Amsterdam: Amsterdam University Press.

Brus, A. (2014). Excellence, diversity and growth: A historical biography of the IMISCOE Research Network. IMISCOE. http://imiscoe.org/docman-docs/397-brus-2014-imiscoe-biography/file. Last accessed on 3 Aug 2017.

Denzin, N. K., \& Lincoln, Y. S. (Eds.). (1994). Handbook of qualitative research. Thousand Oaks: Sage Publications.

Elliot, A., Norum, R., \& Salazar, N. B. (2017). Methodologies of mobility: Ethnography and experiment. Oxford: Berghahn Books.

Iosifides, T. (2011). Qualitative methods in migration studies: A critical realist perspective. Farnham: Ashgate.

Mahoney, J. (2007). Qualitative methodology and comparative politics. Comparative Political Studies, 40(2), 122-144. https://doi.org/10.1177/0010414006296345.

Martiniello, M., \& Rath, J. (2014). Immigrant incorporation studies in Europe: An introduction. In M. Martiniello \& J. Rath (Eds.), An introduction to immigrant incorporation studies: European perspectives (pp. 11-21). Amsterdam: Amsterdam University Press.

Strauss, A. L., \& Corbin, J. M. (1990). Basics of qualitative research: Grounded theory procedures and techniques. Newbury Park: Sage Publications.

Triandafyllidou, A., \& Gropas, R. (2015). What Is Europe? London: Palgrave.

Vargas-Silva, C. (Ed.). (2012). Handbook of research methods in migration. Cheltenham: Edward Elgar.

Voloder, L., \& Kirtipchenko, L. (2013). Insider research on migration and mobility: International perspectives on researcher position. London: Routledge.

Yin, R. K. (2010). Qualitative research from start to finish. New York: Guilford Press.

Zapata-Barrero, R. (2009). Political discourses about borders: On the emergence of a European political community. In H. Lindahl (Ed.), A right to inclusion or exclusion? Normative faultlines of the EU's area of freedom, security and justice (pp. 15-33). Oxford: Hart Publishing.

Open Access This chapter is licensed under the terms of the Creative Commons Attribution 4.0 International License (http://creativecommons.org/licenses/by/4.0/), which permits use, sharing, adaptation, distribution and reproduction in any medium or format, as long as you give appropriate credit to the original author(s) and the source, provide a link to the Creative Commons license and indicate if changes were made.

The images or other third party material in this chapter are included in the chapter's Creative Commons license, unless indicated otherwise in a credit line to the material. If material is not included in the chapter's Creative Commons license and your intended use is not permitted by statutory regulation or exceeds the permitted use, you will need to obtain permission directly from the copyright holder.

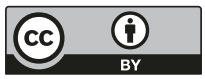

